\title{
Creating New Consultation Programs in Community Mental Health Centers: Analysis of a Case Study
}

Cary Cherniss, Ph.D.*

ABSTRACT: A primary prevention program, initiated in a community mental health center, never became fully operational. Analysis suggests that failure to include recipients in initial planning, an unrealistic time table, insufficient institutional support for innovation, the project leader's organizational marginality, and the institutional constraints created by commitment to direct treatment of troubled individuals were factors that contributed to the project's failure. Several recommendations are presented. The most novel and important one is that systems-oriented, preventive mental health work should be based in a separate, distinct institution.

Growing numbers of mental health workers in recent years have become interested in developing consultation and education programs. Many believe that the creation of more direct treatment programs at this time is a dubious policy because they never reach many individuals who need them and also because, even at their best, such services are not always successful (Albee, 1959). A preventive approach that focuses on community systems and caretakers rather than on individual cases has thus received increasing consideration and support from the mental health fields. Unfortunately, efforts to expand activity in these areas meet with many problems. As usual, our aspirations seem to far exceed what we so far have been able to accomplish.

When the community mental health center concept was first enacted over 10 years ago, "consultation and education" was one of the "five essential services" to be provided. Thus many of the efforts in this area have occurred within the institutional context of the community mental health center. In theory, the community mental health center would provide institutional support and sustenance for these preventive, systems-oriented mental health programs. In practice, however, community mental health centers probably have constituted institutional constraints to these programs at least as often as they have supported them.

During the last 2 years, I have been involved in or have observed at close range a number of attempts to develop consultation and education programs in a community mental health center. Most who know this setting would agree that this center is unusually "progressive" in ethos and staffing and that it avoids many of the pitfalls mentioned by Reiff (1966) and other critics. Many

${ }^{*} D r$. Cherniss is an Assistant Professor of Psychology, University of Michigan, 529 Thompson Street, Ann Arbor 48104. Deborah Cherniss, Gretchen Gardner, Biff Rosalick, Carol Smokler, and Gene Utke read an earlier draft of this paper and provided many helpful comments. 
of the staff have received formal and informal training in consultation and have engaged in its practice. Nevertheless, every consultation or education program I know of has been plagued by serious problems, and several never got off the ground. In other words, technology and commitment have not been enough; organization dynamics and constraints dictated by the institutional contexts in which we work have been equally important determinants of the occasional successes and frequent failures.

In the space of one paper, I cannot provide an exhaustive description of our experiences. However, I can summarize briefly one program's history and its institutional context and then present a small number of issues that seemed instrumental in the program's demise. The analysis suggests that the institutional dynamics of community mental health centers are obstacles to this type of activity, and that a new, autonomous institution for preventive interventions is needed.

\section{HISTORY OF THE PROJECT}

In the spring of 1973, I first conceived the idea of developing a program of group consultation to public school teachers. During the previous 6 months, I had been involved in another school consultation program at the center. This particular center had been conducting school consultation programs for at least 6 years when I first approached the staff with my idea. However, to my knowledge there had not been any center-sponsored formal, on-going program of group consultation with teachers. The initial plan was to establish a number of weekly, voluntary "discussion groups" that would be offered to new teachers. The basic model for the project has been described elsewhere (Sarason, Levine, Goldenburg, Cherlin, \& Bennet, 1966).

During the spring and summer of 1973, the proposed program was discussed with the appropriate administrative staff at the center and in the school systems where it would be offered. During August and September, I selected and brought together five other staff members from the center who would lead the groups. Clearance for the project was secured by midSeptember and a form letter of invitation was sent to the teachers.

The initial response to the letter was minimal. Thus during the next 6 weeks, staff members from the project met with groups of elementary teachers in one of the systems in order to describe the project more fully. We soon found, however, that in addition to the problem encountered in initially reaching and communicating with the potential recipients, we also faced problems around scheduling.

Setting up initial meetings with the teachers after school proved to be time consuming, also, and by early January, 1974, we still had not met with all the teachers. Then two of the original six staff working on the project announced that they would have to withdraw from the project because of heavy time commitments to other center programs. A third project member had missed a number of meetings and also was finding it increasingly difficult to sustain his involvement in the face of heavy commitments elsewhere. At this point there 
were no other staff members in the center who were free to participate in the project. Thus we decided to abandon the project, even though by this time there was enough teacher interest to start conducting discussion groups.

\section{CRITICAL ISSUES IN THE PROJECT'S FAILURE}

The brief account presented above suggests some of the key problems instrumental in the failure of a new consultation program. This section presents in more detail some important underlying organizational dynamics and our responses to them. First, it deals with those issues inherent in our approach to the relationship with the schools and then explores some organizational factors within the center itself that handicapped the projects.

\section{The Approach to the Schools}

Three central problems existed in our approach to the schools. First, we failed to involve the "target" of our intervention, the teachers, directly in our planning. This prevented us from acquiring useful knowledge. The argument that the implementers of a program should be involved in its planning often seems to be based largely on some vague democratic ethos or a desire to be "diplomatic" and win support. Concerns about democracy are legitimate, but our experiences suggest that adequate "reality testing" also requires an all too rare collaboration between mental health consultants and their consultees. For example, if two or three teachers had been part of our initial planning group, they could have informed us of scheduling conflicts, or warned us that a form letter would probably not be read. Socially isolated from the teachers and the insights they could have offered us, we made mistakes that, in retrospect, contributed to the project's ultimate failure.

The second problem characterizing our approach to the schools concerned our own institutional label and the expectations it created. We had identified ourselves in the introductory letter as staff from a "mental health" center offering "mental health consultation." Several school administrators suggested that teachers initially avoided our invitation to participate because of our mental health label, and many teachers may have perceived the program as "group therapy" or "mental health" for teachers.

One final problem in our approach to the schools was our failure to predict accurately the time perspective. Contacts with the schools on the proposed project began the preceding spring and continued throughout the summer. We had hoped to get started by mid-September, but this proved to be unrealistic. Part of the problem already has been suggested: Difficulties in scheduling and the inadequacy of our initial contact with teachers forced us to devote more time and energy to these early phases than we had anticipated. This in turn led to other problems: First, growing impatience encouraged us to attempt shortcuts that proved to be costly mistakes. Also, as planning dragged on longer than expected, morale and confidence dropped. This de- 
cline in morale probably contributed to the eventual loss of staff from the project.

However, the issue of time perspective is a more general one, which goes beyond unexpected delays. In his book on the creation of new settings, Sarason (1972) devotes much attention to the leader's time perspective and its impact on a new setting in its formative period. Our experiences provide strong support for most of Sarason's points. Interestingly, I was quite familiar with Sarason's warnings about time perspective, endorsed them, and had them in mind when I was involved in the project. In fact, I believe it was my understanding of this notion that sustained me. However, there is nothing in Sarason's work that helped me judge in the beginning what a realistic time table should be. More description and analysis of new programs clearly is needed if we are to avoid the detrimental psychological consequences of an unrealistic time perspective.

\section{Some Important Organizational Factors Within the Center}

Frequently providers of service tend to be other-directed in their analyses of the helping process. Thus, in work with individuals, problems in achieving therapeutic progress often are attributed to "resistance," "dependency," or "transference" on the part of the client. Similar constructs often are utilized by consultants in explaining difficulties encountered in work with social systems. However, as Goldenberg (1971) has argued, the internal organization of the help giver's own setting also influences the helping process. In thinking about my own attempts to create a consultation program within a community mental health center, certain aspects of the center's internal organization and functioning, and the proposed program's relationship to the host organization, did seem to influence the project's course.

First, the center's organizational structure made it easy for a staff member to initiate a program but difficult to sustain it. The center was a highly decentralized organization in which staff were given considerable autonomy. It thus was easy for staff to become involved in a new program; however, they did not necessarily receive institutional support for their efforts. This institutional climate can be injurious to new, innovative projects that require nurturance and time to reach fruition, especially when other difficulties are experienced.

Another factor working against the program was the relative expendability of preventive approaches. Although the director and many staff verbally endorsed preventive programs and many staff had the opportunity to engage in such activity, over time the center has made strong institutional commitments to direct client service. These commitments, despite the best of intentions, tend to take priority and interfere with the development of a viable, community-oriented preventive program. For instance, one staff member in the discussion group project had to withdraw when he was reassigned to a halfway house; another withdrew when her involvement in counseling and other direct service activities became too time consuming. 
The existence of direct treatment commitments works against preventive programming in at least two ways. First, once such commitments are made, they incur a strong moral and legal obligation. For instance, in the case of the halfway house, residents in such a setting require continuous supervision and care from staff. In such a program, staff sometimes must make great sacrifices to ensure that there is "coverage." More generally, if any client service program is not available when it is supposed to be, the consequences may be grave. Also, no matter what the center's own ethos may be, the community expects mental health services to be available on demand. Thus a mental health center that fails to meet its direct service obligations will be seen as professionally irresponsible and will lose community support. These moral expectations thus will cause direct treatment to assume higher institutional priority.

The development of direct service programs in a mental health center also works against preventive programming because client demand almost always escalates. As Albee (1959) and others have demonstrated, potential demand for mental health services far exceeds supply. Thus whenever a new, direct treatment program is created, it soon has a waiting list. This heavy demand for service makes it unlikely that a treatment program will be curtailed, and it is likely that over time the direct service program will tend to grow, pulling more resources away from prevention. Thus, despite rhetoric and good intentions, institutional pressures in even the most "progressive" mental health center will tend to favor direct treatment to the detriment of consultation, education, and other forms of prevention.

One other internal factor, the leader's organizational marginality, seemed to work against this project. At the time the project began, I had joint appointments at the center and at the university. Holding only a one-quarter time appointment at the center, I spent less time at the center than did other staff and lacked any formal organizational authority or status.

My marginality worked against the program in a number of ways. First, I was not in a position to influence the organizational priorities that could affect the project's viability. Informal modes of influence were of course available to me; but, ultimately, important policy decisions were made elsewhere. Also, as a marginal part-time staff member, I often received important information about organizational changes later than did many other staff. For instance, when one of the project's staff was promoted and assigned to a commitment that would make it impossible for him to continue, I did not learn about the decision until some time after it had been made. By that time, it was impossible to find a replacement. If I had been less marginal at the center, I might have been able to react to this change more quickly and effectively.

My own organizational marginality may have diminished the center's commitment to the project. The idea for the program, as noted above, originated with me and I assumed total responsibility for its development. There was a strong tendency to regard the program as my program rather than the center's program, and there may not have been the same commitment to it as 
there might have been to a program initiated by a center administrator and directed by a full-time staff member.

Within the program my organizational marginality may have reduced the staff's commitment. For instance, if a staff member associated with the project felt that he or she at some point had to choose between my project and a regular center program favored by a regular supervisor, it is likely that the staff member's commitment would be to the latter. Two of the five project staff members actually indicated that my organizational marginality was a factor when they left the project to concentrate on other commitments.

\section{CONCLUSIONS}

In this paper I have attempted to show that even when there exists motivation, commitment, and expertise, organizational dynamics can impede the development of consultation and education programs in community mental health centers. Within the limited scope of one paper, I have used a case study of a school consultation project to suggest a number of specific organizational problems. First, in approaching the schools, serious problems arose because the consultants lacked necessary information about the teacher's systems. Also, the consultants' identification with the mental health label contributed to the teachers' misperception of the project's aims. Third, an unrealistic time table led to unnecessary errors and demoralization. Internally the center's organizational climate made it easy to initiate the project but difficult to sustain it. Also, the project leader's organizational marginality tended to decrease its viability. Finally, despite verbal support for preventive activity, direct treatment commitments tended to receive institutional support at the expense of preventive programs.

In drawing implications from this analysis, caution is necessary. Any generalizations based on a single case must be seen as tentative. However, many of the experiences presented here confirm ideas that have emerged from previous studies of the creation and development of new institutional programs (Goldenberg, 1971; Cherniss, 1972). Thus although more research is needed, it may not be premature to suggest some important lessons from our experience.

\section{Early Planning}

Recipients of the service must be involved in its early planning. As noted above, this is neither a luxury nor a noble gesture of diplomacy, nor even a moral imperative derived from some vague democratic ethos. It is a practical means of controlling for systemic factors that could destroy a proposed project.

\section{Formative Period of Innovative Programs}

In fluid, complex organizational environments, special mechanisms should be created to sustain small, innovative programs during their formative periods. The most appropriate mechanism will depend on the nature of the setting. However, if innovations are to occur in organizations, 
special mechanisms must be developed to sustain them during the most difficult early phases. An organizational structure that facilitates initiation of new programs is not enough. It may even be better to create conditions in which fewer innovative programs are created but when they are created, to take them more seriously and give them more institutional support. To create such conditions, less entrepreneurism and fluidity and greater deliberation and purposefulness in organizational functioning may be necessary (Clark, 1956).

\section{The Creator of Innovative Program}

The creator of an innovative program should not be a marginal member of the host organization. Obviously there are instances in which marginal members of organizations have created viable new programs. However, as suggested above, the likelihood of success decreases when the new program is identified with a marginal or deviant individual.

\section{Creation of a Separate Prevention Institution}

Rather than attempt to create systems-oriented, primary prevention programs in community mental health centers, we should create a new, totally separate institution for such programs. This is perhaps the most radical and important proposition of all, and it is one suggested by a number of points in this analysis. For instance, the project's institutional identification with a "mental health" center complicated the approach to the schools. Also, the inherent constraints of clinical responsibility, community expectation, and the ongoing demand for psychological treatment make it difficult for any mental health center offering treatment to give equal priority to prevention. Over time, treatment programs tend to choke out preventive efforts.

This proposition is not new. As early as 1966, Reiff was pointing to the futility of attempting to create systems-oriented, preventive programs within community mental health centers. Reiff's analysis focused on ideology and manpower. In this paper, I suggested that even where the ideology is favorable and the manpower available, organizational dynamics will create severe problems for consultation, education, and other forms of primary prevention in community mental health centers. Thus not only do we need a new profession of systems-oriented interventionists as Reiff advocated; we also need a new institutional base to support their efforts.

Although the medical care system in this country is a dubious model for community mental health, there is one feature we might do well to emulate in certain respects. In most instances, medical treatment and prevention are conducted within different institutional contexts. Public health departments were created in order to advance and coordinate preventive health programs. Such departments generally eschew direct service and devote all their energies to the cause of prevention. Over time, public health has developed a distinctive professional and institutional identity which now is recognized and supported by most communities.

When I have proposed the creation of a separate, autonomous institution 
whose sole mission would be the development of programs that would prevent rather than treat psychological disorders, I have encountered two primary criticisms. First, it is argued that in providing direct service to clients community mental health centers thereby acquire greater credibility for consultation and education programs. However, our experiences (some of which are described above) suggest that credibility is specific rather than general. If a consultant comes from an institution that provides good psychological treatment, the consultant's credibility will be in the area of treatment rather than prevention. There is no reason to assume that an institution that provides credible treatment for individuals will also be credible in intervening in the community systems in a primary preventive way. In fact, when a worker from a community mental health center approaches a school and tries to suggest that he or she can also improve the functioning of the social system, the response is likely to be a mixture of surprise and mirth. Thus it is not clear that a consultant from a community mental health center is necessarily more credible because he or she comes from an institution that provides direct treatment to individuals; in fact, association with such an institution can detract from a consultant's credibility in areas involving a systems-level intervention.

A second argument against this proposal is that the competition between preventive and treatment orientations discussed here would continue to occur even if the activities were housed in separate institutions. There is no question that this would be the case. However, as the original 13 American colonies concluded and then demonstrated almost 200 years ago, independence is preferable. For independence permits opportunity for greater recognition, a stronger sense of identity, and greater freedom to break with past traditions. Clearly a new, prevention-oriented institution would face many political struggles with competing institutional interests, just as this nation's conflict with England continued long after independence was grudgingly granted. However, the cause of prevention would be better served in a separate institution that had direct access to the public and its elected representatives and which clearly stood for a distinctive new approach that aims at change in systems rather than in individuals.

In conclusion, direct service to those in need obviously is worthy of support. However, social interventions that ultimately lead to the prevention of personal and interpersonal difficulties also are worthy of support. If the analysis presented in this paper is valid, attempts to develop preventive programs within existing community mental health centers will meet with arduous and unnecessary difficulties. For these reasons, I advocate institutional independence for systems-level, preventive interventions.

\section{REFERENCES}

Albee, G. W. Mental health manpower trends. New York: Basic Books, 1959.

Cherniss, C. New settings in the University: Their creation, problems, and early development. Unpublished doctoral dissertation, Yale University, 1972.

Clark, B. R. Adult education in transition: A study of institutional insecurity. University of California Publications in Sociology and Social Institutions, 1956, 1, 43-202. 
Goldenberg, I. I. Build me a mountain: Youth, poverty, and the creation of new settings. Cambridge: Massachusetts Institute of Technology Press, 1971.

Reiff, R. Mental health manpower and institutional change. American Psychologist, 1966, 21, 540-548.

Sarason, S. B. The creation of settings and the future societies. San Francisco: Jossey-Bass, 1972.

Sarason, S. B., Levine, M., Goldenberg, I. I., Cherlin, D., and Bennet, E. Psychology in community settings. New York: Wiley, 1966. 